\title{
Określanie wielkości emisji zanieczyszczeń do powietrza towarzyszących eksploatacji złóż ropy naftowej i gazu ziemnego metodą wskaźnikową
}

\begin{abstract}
W artykule omówiono dostępne w literaturze krajowej oraz zagranicznej wskaźniki emisji dla kotłów i innych urządzeń zasilanych gazem ziemnym, które pozwalają na obliczenie wprowadzanych do powietrza zanieczyszczeń - w sposób najbardziej poprawny - przez zakłady prowadzące eksploatację złóż ropy naftowej i gazu ziemnego. Opisano także metodę obliczania emisji zanieczyszczeń do powietrza na podstawie wskaźników emisji dla danego typu urządzeń, która potencjalnie może być wykorzystana do obliczania emisji z poszczególnych urządzeń i instalacji.
\end{abstract}

Słowa kluczowe: emisja zanieczyszczeń, wskaźniki emisji.

\section{Determination of the emission of air pollutants associated with the exploitation of oil and gas by emission factors}

The article discusses available in Polish and foreign literature, emission factors for boilers and other equipment powered by natural gas, which allow the calculation of pollutants released into the air in the most appropriate way, by the facilities of oil and natural gas exploitation. Describes a method for calculating emissions into the air, from the emission factors for the type of equipment, that could potentially be used, to calculate emissions from individual facilities and installations.

Key words: emissions, emission factors.

\section{Wstęp}

Zgodnie z przepisami prawa ochrony środowiska prowadzący instalacje oraz użytkownicy urządzeń są zobowiązani do ciągłych lub okresowych pomiarów wielkości emisji zanieczyszczeń. Do prowadzenia ciągłych pomiarów wielkości emisji zobligowani są prowadzący instalację oraz użytkownicy urządzeń w razie wprowadzania do środowiska znacznych ilości substancji lub energii o łącznej nominalnej mocy cieplnej nie mniejszej niż 100 MW. Okresowe pomiary emisji do powietrza prowadzi się dla instalacji spalania paliw wymagających pozwolenia na wprowadzanie gazów lub pyłów do powietrza albo pozwolenia zintegrowanego, w tym źródeł spalania paliw, dla których określa się standardy emisyjne.

Przy pozostałych instalacjach nieobjętych pomiarami, dla których nie ma obowiązku prowadzenia pomiarów, należy wykorzystywać opracowane w literaturze bądź własne wskaźniki emisji.
Przypadki, w których wymagane są ciągłe lub okresowe pomiary emisji z instalacji albo urządzenia, a także częstotliwości prowadzenia pomiarów określa Rozporzadzenie Ministra Środowiska z dnia 30 października 2014 r. w sprawie wymagań w zakresie prowadzenia pomiarów wielkości emisji oraz pomiarów ilości pobieranej wody (Dz.U. z 2014 r., poz. 1542).

Możliwość określenia sposobów ustalania wielkości emisji dla poszczególnych rodzajów instalacji daje Ustawa z dnia 17 lipca 2009 r. o systemie zarządzania emisjami gazów cieplarnianych i innych substancji (Dz.U. z 2015 r., poz. 2278).

Obliczenia wielkości emisji powinny obejmować wszystkie rodzaje substancji emitowanych do powietrza oraz wszelkie źródła emisji eksploatowane przez prowadzącego instalację. Powinny również wykorzystywać najlepszą spośród dostępnych metod obliczeniowych, $\mathrm{tj}$.: 
- metodę opartą na wynikach pomiarów ciągłych,

- metodę opartą na wynikach pomiarów okresowych, bilansach lub wskaźnikach ogólnych o wysokiej pewności (dotyczy głównie wskaźników emisji dwutlenku węgla),

- z użyciem danych literaturowych (wskaźniki literaturowe).

Wskaźniki emisji substancji do powietrza nie są określane aktem prawnym. Nie ma obowiązku stosowania wskaźników podanych przez Krajowy Ośrodek Bilansowania i Zarządzania Emisjami (KOBiZE) czy też zamieszczo- nych przez nieistniejące już Ministerstwo Ochrony Środowiska, Zasobów Naturalnych i Leśnictwa w Materiatach informacyjno-instruktażowych MOŚZNiL (seria 1/96, Warszawa, kwiecień 1996 r.). Dokumenty te można traktować jako materiał pomocniczy przy ustalaniu wielkości emisji. Podmioty składające sprawozdania z tytułu wprowadzania do powietrza zanieczyszczeń mogą więc korzystać z wszystkich dostępnych wskaźników emisji oraz metod obliczeniowych.

\section{Obliczanie emisji zanieczyszczeń do powietrza na podstawie wskaźników emisji dla danego typu urządzeń}

Metoda ta oparta jest na założeniu stałych wartości wskaźników dla poszczególnych substancji w zależności od danego typu urządzenia (rodzaj urządzenia, rodzaj paliwa, moc) i przemnożeniu ich przez zużytą przez dane urządzenie ilość paliwa wyrażoną w jednostkach objętości, masy lub energii.

Wielkości emisji są uzależnione od rodzaju i ilości zużycia paliwa, parametrów paliwa: wartości opałowej, zawartości popiołu oraz zawartości siarki. Ogólnym wzorem służącym do obliczania wielkości emisji na podstawie wskaźnika emisji na jednostkę zużytego paliwa jest:

$$
E=B \cdot W
$$

gdzie:

$E$ - emisja substancji,

$B$ - zużycie paliwa,

$W$-wskaźnik emisji na jednostkę zużytego paliwa.

Poniżej przedstawiono ogólny wzór służący do obliczania wielkości emisji na podstawie wskaźnika emisji na energię chemiczną wprowadzoną w paliwie.

$$
E=B \cdot W_{o} \cdot W
$$

gdzie:

$E$ - emisja substancji,

$B$ - zużycie paliwa,

$W_{o}$ - wartość opałowa paliwa,

$W$ - wskaźnik emisji na gigadżul energii chemicznej zawartej w paliwie.

Wartości emisji zanieczyszczeń do powietrza obliczone przy pomocy ogólnie dostępnych wskaźników niejednokrotnie bardzo odbiegają od rzeczywistych, zawyżając je lub też zaniżając. Sytuacje takie będą miały miejsce szczególnie w przypadku urządzeń nowoczesnych, na których wykonywane są regularnie przeglądy konserwacyjne oraz optymalizacja warunków pracy (bardzo niska rzeczywista emisja zanieczyszczeń), jak również przy urządzeniach używanych od wielu lat, które uległy już w znacznym stopniu wyeksploatowaniu, a regulacja warunków ich pracy nie jest możliwa lub mocno ograniczona (wysoka rzeczywista emisja zanieczyszczeń). Metoda ta w większości przypadków daje jednak bardzo zbliżone wyniki do wartości faktycznych, jednocześnie jest bardzo prosta i szybka w użyciu.

\section{Wskaźniki emisji dla kotłów i innych urządzeń zasilanych gazem ziemnym}

Dla danego urządzenia oraz stosowanego w nim paliwa istnieją wskaźnikowe wartości emisji różnych zanieczyszczeń gazowych oraz pyłowych. Obecnie w kraju są wskaźniki do obliczeń emisji zanieczyszczeń pochodzące z materiałów informacyjno-instruktażowych Ministerstwa Ochrony Środowiska, Zasobów Naturalnych i Leśnictwa (MOŚZNiL) z 1996 roku i zawierają wartości sugerowane dla urządzeń zasilanych gazem wysokometanowym oraz przeliczone wartości wskaźników dla gazu zaazotowanego (tablice 1 i 2) [7]. Natomiast wskaźniki rekomendowane przez Krajowy Ośrodek Bilansowania i Zarządzania Emisjami pochodzą z dokumentu Wskaźniki emisji zanieczyszczeń ze spalania paliw - kothy o nominalnej mocy cieplnej do 5 MW, styczeń 2015 [4]. Obejmują one, w przeciwieństwie do wersji wcześniejszych oraz bazowego opracowania Ministerstwa Ochrony Środowiska, Zasobów Naturalnych i Leśnictwa (MOŚZNiL) z 1996 roku [7], wyłącznie wskaźniki dla urządzeń zasilanych gazem wysokometanowym (tablica 3).

Zastosowane przeliczenie wartości współczynników dla gazu zaazotowanego polega na podzieleniu danego wskaźnika emisji przez stosunek wartości opałowej gazu wysokometanowego (za standardową przyjmując wartość 39,5 MJ/m³) do gazu zaazotowanego (za standardową przyjmując wartość $27,9 \mathrm{MJ} / \mathrm{m}^{3}$ ).

Ponieważ w obliczeniach współczynników (wyrażonych $\mathrm{w} \mathrm{kg} / 10^{6} \mathrm{~m}^{3}$ ) przyjęto założenia, że cała siarka oraz węgiel zawarte w gazie są konwertowane do $\mathrm{CO}_{2}$ oraz $\mathrm{SO}_{2}$, używanie zastosowanej konwersji opartej na stosunku wartości opa- 
Tablica 1. Wskaźniki emisji zanieczyszczeń dla urządzeń zasilanych gazem ziemnym wysokometanowym, pochodzące z materiałów informacyjno-instruktażowych MOŚZNiL

\begin{tabular}{|c|c|c|c|c|c|}
\hline \multirow{2}{*}{ Zanieczyszczenie } & \multirow{2}{*}{$\begin{array}{l}\text { Jednostka } \\
\text { wskaźnika }\end{array}$} & \multicolumn{4}{|c|}{ Wydajność cieplna [MW] } \\
\hline & & $\geq 30$ & $5,5 \div 30$ & $1,4 \div 5,5$ & $\leq 1,4$ \\
\hline Tlenki siarki $\left(\mathrm{SO}_{\mathrm{X}} / \mathrm{SO}_{2}\right)$ & \multirow{5}{*}{$\mathrm{kg} / 10^{6} \mathrm{~m}^{3}$} & $2 \cdot S$ & $2 \cdot S$ & $2 \cdot S$ & $2 \cdot S$ \\
\hline Tlenki azotu $\left(\mathrm{NO}_{\mathrm{X}} / \mathrm{NO}_{2}\right)$ & & $\begin{array}{l}4800^{1)} \\
7500^{2)}\end{array}$ & 3700 & 1920 & 1280 \\
\hline Tlenek węgla $(\mathrm{CO})$ & & 270 & 270 & 270 & 360 \\
\hline Ditlenek węgla $\left(\mathrm{CO}_{2}\right)$ & & 1964000 & 1964000 & 1964000 & 1964000 \\
\hline Pył zawieszony całkowity (TSP) & & 12,0 & 14,5 & 14,5 & 15,0 \\
\hline
\end{tabular}

$\mathrm{S}$ - zawartość siarki całkowitej wyrażona w miligramach na metr sześcienny $\left[\mathrm{mg} / \mathrm{m}^{3}\right]$.

${ }^{1)}$ Wartość dla palników pionowych.

${ }^{2)}$ Wartość dla palników poziomych.

Tablica 2. Wskaźniki emisji zanieczyszczeń dla urządzeń zasilanych gazem ziemnym zaazotowanym, pochodzące z materiałów informacyjno-instruktażowych MOŚZNiL

\begin{tabular}{|c|c|c|c|c|c|}
\hline \multirow{2}{*}{ Zanieczyszczenie } & \multirow{2}{*}{$\begin{array}{l}\text { Jednostka } \\
\text { wskaźnika }\end{array}$} & \multicolumn{4}{|c|}{ Wydajność cieplna [MW] } \\
\hline & & $\geq 30$ & $5,5 \div 30$ & $1,4 \div 5,5$ & $\leq 1,4$ \\
\hline Tlenki siarki $\left(\mathrm{SO}_{\mathrm{X}} / \mathrm{SO}_{2}\right)$ & \multirow{5}{*}{$\mathrm{kg} / 10^{6} \mathrm{~m}^{3}$} & $1,4 \cdot \mathrm{S}$ & $1,4 \cdot S$ & $1,4 \cdot S$ & $1,4 \cdot \mathrm{S}$ \\
\hline Tlenki azotu $\left(\mathrm{NO}_{\mathrm{X}} / \mathrm{NO}_{2}\right)$ & & $\begin{array}{l}3360^{1)} \\
5250^{2)}\end{array}$ & 2590 & 1345 & 900 \\
\hline Tlenek węgla (CO) & & 190 & 190 & 190 & 225 \\
\hline Ditlenek węgla $\left(\mathrm{CO}_{2}\right)$ & & 1375000 & 1375000 & 1375000 & 1375000 \\
\hline Pył zawieszony całkowity (TSP) & & 8,5 & 10,1 & 10,1 & 10,5 \\
\hline
\end{tabular}

$\mathrm{S}$ - zawartość siarki całkowitej wyrażona w miligramach na metr sześcienny $\left[\mathrm{mg} / \mathrm{m}^{3}\right]$.

${ }^{1)}$ Wartość dla palników pionowych.

2) Wartość dla palników poziomych.

łowej poszczególnych gazów jest niezasadne. Przykładowo, przy takiej samej zawartości siarki w obu gazach otrzymane ilości emitowanych substancji nie powinny się zmienić, jednak przy zastosowaniu zalecanych wskaźników ilość emitowanego $\mathrm{SO}_{2}$ będzie w przypadku gazu zaazotowanego znacznie niższa. Dlatego dla $\mathrm{CO}_{2}$ oraz $\mathrm{SO}_{\mathrm{x}}$ zaleca się stosowanie takich wskaźników jak dla gazu wysokometanowego.

Istnieją także wskaźniki opracowane dla poszczególnych instalacji pochodzące z zagranicznych źródeł literaturowych, np. wskaźniki emisji publikowane w biuletynach API, w dokumentach US EPA czy EMEP/EEA.

Przedstawione poniżej wskaźniki emisji zanieczyszczeń rekomendowane są przez European Environment Agency i pochodzą z dokumentu EMEP/EEA Air Pollutant Emission Inventory Guidebook 2013 [2].
Tablica 3. Wskaźniki emisji zanieczyszczeń dla urządzeń zasilanych gazem ziemnym zalecane przez KOBiZE [4]

\begin{tabular}{|c|c|c|c|}
\hline \multirow{2}{*}{ Zanieczyszczenie } & \multirow{2}{*}{$\begin{array}{l}\text { Jednostka } \\
\text { wskaźnika }\end{array}$} & \multicolumn{2}{|c|}{ Nominalna moc cieplna kotła $[\mathrm{MW}]$} \\
\hline & & $\leq 0,5$ & $>0,5 \div \leq 5$ \\
\hline Tlenki siarki $\left(\mathrm{SO}_{X} / \mathrm{SO}_{2}\right)$ & \multirow{5}{*}{$\mathrm{g} / \mathrm{m}^{3}$} & \multicolumn{2}{|c|}{$0,002 \cdot \mathrm{S}$} \\
\hline Tlenki azotu $\left(\mathrm{NO}_{\mathrm{X}} / \mathrm{NO}_{2}\right)$ & & 1,52 & 1,75 \\
\hline Tlenek węgla (CO) & & 0,30 & 0,24 \\
\hline Ditlenek węgla $\left(\mathrm{CO}_{2}\right)$ & & \multicolumn{2}{|c|}{2000} \\
\hline Pył zawieszony całkowity (TSP) & & \multicolumn{2}{|c|}{0,0005} \\
\hline
\end{tabular}

$\mathrm{S}-$ zawartość siarki całkowitej wyrażona w miligramach na metr sześcienny $\left[\mathrm{mg} / \mathrm{m}^{3}\right]$.

Wskaźniki w tabelach od 4 do 7 zostały podzielone w zależności od typu i mocy urządzeń i nie obejmują one emisji ditlenku węgla. W tablicach 4-7 oprócz wskaźników podanych przez EMEP/EEA, wyrażonych w g/GJ paliwa, przedstawiono również ich wartości przeliczone dla gazu wysokometanowego (grupy E) oraz zaazotowanego (grupy $\mathrm{L}_{\mathrm{W}} \mathrm{i} \mathrm{L}_{\mathrm{S}}$ ), wyrażone $\mathrm{w} \mathrm{kg} / 10^{6} \mathrm{~m}^{3}$ paliwa.

W tablicach 4-7 wartości wskaźników dla gazów zaazotowanych zostały przeliczone zgodnie $\mathrm{z}$ metodą zalecaną przez US EPA, tj. podzielono dany wskaźnik emisji przez stosunek 
Tablica 4. Wskaźniki emisji zanieczyszczeń dla małych kotłów o mocy poniżej 50 kW zasilanych gazem ziemnym, zalecane przez EMEP/EEA [2]

\begin{tabular}{|c|c|c|c|c|}
\hline \multirow{4}{*}{ Zanieczyszczenie } & \multicolumn{4}{|c|}{ Jednostka wskaźnika } \\
\hline & g/GJ paliwa & \multicolumn{3}{|c|}{$\mathrm{kg} / 10^{6} \mathrm{~m}^{3}$ paliwa } \\
\hline & - & \multicolumn{3}{|c|}{ kaloryczność paliwa* } \\
\hline & - & $\begin{array}{c}36,18 \mathrm{MJ} / \mathrm{m}^{3} \\
\text { (gaz ziemny wysokometanowy, } \\
\text { grupa E) }\end{array}$ & $\begin{array}{c}28,61 \mathrm{MJ} / \mathrm{m}^{3} \\
\text { (gaz ziemny zaazotowany, } \\
\text { grupa } \mathrm{L}_{\mathrm{W}} \text { ) }\end{array}$ & $\begin{array}{c}25,98 \mathrm{MJ} / \mathrm{m}^{3} \\
\text { (gaz ziemny zaazotowany, } \\
\text { grupa } \mathrm{L}_{\mathrm{S}} \text { ) }\end{array}$ \\
\hline Tlenki azotu $\left(\mathrm{NO}_{\mathrm{x}}\right)$ & 42,0 & 1520 & 1202 & 1091 \\
\hline Tlenek węgla (CO) & 22,0 & 796 & 629 & 572 \\
\hline LZO & 1,8 & 65 & 51 & 47 \\
\hline Ditlenek węgla $\left(\mathrm{CO}_{2}\right)$ & - & - & - & - \\
\hline Pył całkowity (TSP) & 0,2 & 7 & 6 & 5 \\
\hline PM-10 & 0,2 & 7 & 6 & 5 \\
\hline PM-2,5 & 0,2 & 7 & 6 & 5 \\
\hline Ditlenek siarki $\left(\mathrm{SO}_{2}\right)$ & 0,3 & 11 & - & - \\
\hline
\end{tabular}

* Średnie wartości opałowe gazu ziemnego otrzymane na podstawie pomiarów przeprowadzonych w ramach pracy INiG - PIB [3].

Tablica 5. Wskaźniki emisji zanieczyszczeń dla kotłów średniej wielkości o mocy od 50 kW do 1 MW zasilanych gazem ziemnym, zalecane przez EMEP/EEA [2]

\begin{tabular}{|c|c|c|c|c|}
\hline \multirow{4}{*}{ Zanieczyszczenie } & \multicolumn{4}{|c|}{ Jednostka wskaźnika } \\
\hline & g/GJ paliwa & \multicolumn{3}{|c|}{$\mathrm{kg} / 10^{6} \mathrm{~m}^{3}$ paliwa } \\
\hline & - & \multicolumn{3}{|c|}{ kaloryczność paliwa* } \\
\hline & - & $\begin{array}{c}36,18 \mathrm{MJ} / \mathrm{m}^{3} \\
\text { (gaz ziemny wysokometanowy, } \\
\text { grupa E) }\end{array}$ & $\begin{array}{c}28,61 \mathrm{MJ} / \mathrm{m}^{3} \\
\text { (gaz ziemny zaazotowany, } \\
\text { grupa } \mathrm{L}_{\mathrm{W}} \text { ) }\end{array}$ & $\begin{array}{c}25,98 \mathrm{MJ} / \mathrm{m}^{3} \\
\text { (gaz ziemny zaazotowany, } \\
\text { grupa } \mathrm{L}_{\mathrm{S}} \text { ) }\end{array}$ \\
\hline Tlenki azotu $\left(\mathrm{NO}_{\mathrm{X}}\right)$ & 73,00 & 2641 & 2089 & 1897 \\
\hline Tlenek węgla (CO) & 24,00 & 868 & 687 & 624 \\
\hline LZO & 0,36 & 13 & 10 & 9 \\
\hline Ditlenek węgla $\left(\mathrm{CO}_{2}\right)$ & - & - & - & - \\
\hline Pył całkowity (TSP) & 0,45 & 16 & 13 & 12 \\
\hline PM-10 & 0,45 & 16 & 13 & 12 \\
\hline PM-2,5 & 0,45 & 16 & 13 & 12 \\
\hline Ditlenek siarki $\left(\mathrm{SO}_{2}\right)$ & 1,40 & 51 & - & - \\
\hline
\end{tabular}

* Średnie wartości opałowe gazu ziemnego otrzymane na podstawie pomiarów przeprowadzonych w ramach pracy INiG - PIB [3].

wartości opałowej gazu wysokometanowego do gazu zaazotowanego. Ze względu na występujący w tym przypadku błąd dla $\mathrm{SO}_{\mathrm{x}}$ oraz $\mathrm{CO}_{2}$ wartości tych nie przeliczano. W przypadku określania emisji zanieczyszczeń dla spalania gazu zaazotowanego dla tych substancji należy używać takich samych wskaźników jak dla gazu wysokometanowego.

Wskaźniki emisji dla urządzeń zasilanych gazem ziemnym zawiera również dokument Emission Factor Documentation for AP-42 Section 1.4 Natural Gas Combustion, przygotowany w 1996 roku na potrzeby US Environmental Protection Agency (US EPA) [11]. Przedstawione w raporcie wskaźniki zostały opracowane dla gazu wysokometanowego o zawartości metanu minimum 85\%. Zgodnie z instrukcją zawartą w opracowaniu, w przypadku wykorzystania wskaźników do obliczania emisji z urządzeń spalających paliwo gazowe o niższej kaloryczności należy przemnożyć wartości wskaźników dla $\mathrm{CO}_{2}$ oraz $\mathrm{SO}_{2}$ przez stosunek wartości opałowej gazu wysokometanowego i gazu wykorzystywanego w urządzeniu.

Ponieważ w obliczeniach współczynników przyjęto założenia, że cała siarka oraz węgiel zawarte w gazie są konwertowane do $\mathrm{CO}_{2}$ oraz $\mathrm{SO}_{2}$, używanie zastosowanej konwersji opartej na stosunku wartości opałowej poszczególnych gazów jest niezasadne. Przykładowo, przy takiej samej 
Tablica 6. Wskaźniki emisji zanieczyszczeń dla dużych kotłów o mocy $1 \div 50$ MW zasilanych gazem ziemnym, zalecane przez EMEP/EEA [2]

\begin{tabular}{|c|c|c|c|c|}
\hline \multirow{4}{*}{ Zanieczyszczenie } & \multicolumn{4}{|c|}{ Jednostka wskaźnika } \\
\hline & g/GJ paliwa & \multicolumn{3}{|c|}{$\mathrm{kg} / 10^{6} \mathrm{~m}^{3}$ paliwa } \\
\hline & - & \multicolumn{3}{|c|}{ kaloryczność paliwa* } \\
\hline & - & $\begin{array}{c}36,18 \mathrm{MJ} / \mathrm{m}^{3} \\
\text { (gaz ziemny wysokometanowy, } \\
\text { grupa } \mathrm{E} \text { ) }\end{array}$ & $\begin{array}{c}28,61 \mathrm{MJ} / \mathrm{m}^{3} \\
\text { (gaz ziemny zaazotowany, } \\
\text { grupa } \mathrm{L}_{\mathrm{W}} \text { ) }\end{array}$ & $\begin{array}{c}25,98 \mathrm{MJ} / \mathrm{m}^{3} \\
\text { (gaz ziemny zaazotowany, } \\
\text { grupa } \mathrm{L}_{\mathrm{S}} \text { ) }\end{array}$ \\
\hline Tlenki azotu $\left(\mathrm{NO}_{\mathrm{X}}\right)$ & 40,00 & 1447 & 1144 & 1039 \\
\hline Tlenek węgla (CO) & 30,00 & 1085 & 858 & 779 \\
\hline $\mathrm{LZO}$ & 2,00 & 72 & 57 & 52 \\
\hline Ditlenek węgla $\left(\mathrm{CO}_{2}\right)$ & - & - & - & - \\
\hline Pył całkowity (TSP) & 0,45 & 16 & 13 & 12 \\
\hline PM-10 & 0,45 & 16 & 13 & 12 \\
\hline PM-2,5 & 0,45 & 16 & 13 & 12 \\
\hline Ditlenek siarki $\left(\mathrm{SO}_{2}\right)$ & 0,30 & 11 & - & - \\
\hline
\end{tabular}

* Średnie wartości opałowe gazu ziemnego otrzymane na podstawie pomiarów przeprowadzonych w ramach pracy INiG - PIB [3].

Tablica 7. Wskaźniki emisji zanieczyszczeń dla agregatów prądotwórczych, pomp, sprężarek zasilanych gazem ziemnym, zalecane przez EMEP/EEA [2]

\begin{tabular}{|c|c|c|c|c|}
\hline \multirow{4}{*}{ Zanieczyszczenie } & \multicolumn{4}{|c|}{ Jednostka wskaźnika } \\
\hline & g/GJ paliwa & \multicolumn{3}{|c|}{$\mathrm{kg} / 10^{6} \mathrm{~m}^{3}$ paliwa } \\
\hline & - & \multicolumn{3}{|c|}{ kaloryczność paliwa* } \\
\hline & - & $\begin{array}{c}36,18 \mathrm{MJ} / \mathrm{m}^{3} \\
\text { (gaz ziemny wysokometanowy, } \\
\text { grupa E) }\end{array}$ & $\begin{array}{c}28,61 \mathrm{MJ} / \mathrm{m}^{3} \\
\text { (gaz ziemny zaazotowany, } \\
\text { grupa } \mathrm{L}_{\mathrm{W}} \text { ) }\end{array}$ & $\begin{array}{c}25,98 \mathrm{MJ} / \mathrm{m}^{3} \\
\text { (gaz ziemny zaazotowany, } \\
\text { grupa } \mathrm{L}_{\mathrm{S}} \text { ) }\end{array}$ \\
\hline Tlenki azotu $\left(\mathrm{NO}_{\mathrm{x}}\right)$ & 135,0 & 4884 & 3862 & 3507 \\
\hline Tlenek węgla (CO) & 56,0 & 2026 & 1602 & 1455 \\
\hline LZO & 89,0 & 3220 & 2546 & 2312 \\
\hline Ditlenek węgla $\left(\mathrm{CO}_{2}\right)$ & - & - & - & - \\
\hline Pył całkowity (TSP) & 2,0 & 72 & 57 & 52 \\
\hline PM-10 & 2,0 & 72 & 57 & 52 \\
\hline PM-2,5 & 2,0 & 72 & 57 & 52 \\
\hline Ditlenek siarki $\left(\mathrm{SO}_{2}\right)$ & 0,5 & 18 & - & - \\
\hline
\end{tabular}

* Średnie wartości opałowe gazu ziemnego otrzymane na podstawie pomiarów przeprowadzonych w ramach pracy INiG - PIB [3].

zawartości siarki w obu gazach otrzymane ilości emitowanych substancji nie powinny się zmienić, jednak przy zastosowaniu zalecanych wskaźników ilość emitowanego $\mathrm{SO}_{2}$ będzie w przypadku gazu zaazotowanego znacznie niższa.

W przypadku stosowania wskaźników rekomendowanych przez EMEP/EEA oraz US EPA w celu obliczenia emisji ditlenku węgla $z$ urządzeń zasilanych gazem ziemnym proponuje się stosowanie wskaźnika zalecanego przez American Petroleum Institute (API), który jest spójny ze wskaźnikiem emisji ditlenku węgla zamieszczonym w dokumencie KOBiZE (tablice 3 i 9) i zakłada, że cały węgiel zawarty w spalanym paliwie zostaje przekształcony w ditlenek węgla.
Tablica 8. Wskaźniki emisji zanieczyszczeń dla urządzeń zasilanych gazem ziemnym zalecane przez US EPA [11]

\begin{tabular}{|l|c|}
\hline \multirow{2}{*}{\multicolumn{1}{|c|}{ Zanieczyszczenie }} & Jednostka wskaźnika \\
\cline { 2 - 2 } & $\mathrm{kg} / 10^{6} \mathrm{~m}^{3}$ paliwa \\
\hline Tlenki azotu $\left(\mathrm{NO}_{\mathrm{x}}\right)$ & 800,0 \\
\hline Tlenek węgla $(\mathrm{CO})$ & 1344,0 \\
\hline Ditlenek węgla $\left(\mathrm{CO}_{2}\right)$ & 1920000,0 \\
\hline Pył całkowity $(\mathrm{TSP})$ & 121,6 \\
\hline Ditlenek siarki $\left(\mathrm{SO}_{2}\right)$ & 9,6 \\
\hline Lotne Związki Organiczne $(\mathrm{LZO})$ & 88,0 \\
\hline
\end{tabular}


Tablica 9. Wskaźniki emisji ditlenku węgla dla urządzeń zasilanych gazem ziemnym zalecane przez American Petroleum Institute

\begin{tabular}{|c|c|c|c|c|}
\hline \multirow{2}{*}{ Zanieczyszczenie } & \multicolumn{4}{|c|}{ Jednostka wskaźnika } \\
\cline { 2 - 5 } & $\mathrm{g} /$ GJ paliwa & \multicolumn{3}{|c|}{$\mathrm{kg} / 10^{6} \mathrm{~m}^{3}$ paliwa } \\
\cline { 2 - 5 } & - & \multicolumn{3}{|c|}{ kaloryczność paliwa* } \\
\cline { 2 - 5 } & - & $\begin{array}{c}36,18 \mathrm{MJ} / \mathrm{m}^{3} \\
\text { gaz ziemy wysokometanowy, } \\
\text { grupa E) }\end{array}$ & $\begin{array}{c}28,61 \mathrm{MJ} / \mathrm{m}^{3} \\
\text { gaz ziemny zaazotowany, } \\
\left.\text { grupa } \mathrm{L}_{\mathrm{W}}\right)\end{array}$ & $\begin{array}{c}\text { (gaz ziemny zaazotowany, } \\
\left.\text { grupa } \mathrm{L}_{\mathrm{S}}\right)\end{array}$ \\
\hline Ditlenek węgla $\left(\mathrm{CO}_{2}\right)$ & 55900 & 2022431 & - & - \\
\hline
\end{tabular}

${ }^{*}$ Na podstawie dokumentu API [1].

\section{Podsumowanie}

W artykule przeanalizowana została możliwość zastosowania poszczególnych wskaźników emisji dla kotłów i innych urządzeń zasilanych gazem ziemnym, stosowanych w zakładach prowadzących eksploatację złóż ropy naftowej i gazu ziemnego. Korzystanie z dostępnych wskaźników emisji oraz metod obliczeniowych jest wskazane, gdyż opracowanie indywidualnych wskaźników do stosowania dla wszystkich urządzeń/instalacji w danym zakładzie byłoby praktycznie niewykonalne. $Z$ tych samych powodów oparcie obliczeń emisji wyłącznie na pomiarach emisji także byłoby trudne do wykonania, zwłaszcza z uwagi na koszty badań, którymi należałoby objąć ogromną liczbę obiektów i urządzeń w skali kraju. Jednak w przypadku, gdy istnieją przesłanki, że emisje obliczone przy pomocy rekomendowanych wskaźników są znacznie zawyżone dla danego typu urządzenia, należy posłużyć się wskaźnikami obliczonymi na podstawie wyników emisji z pomiarów okresowych. Za raportowanie na potrzeby systemu opłat za wprowadzanie gazów lub pyłów do powietrza bezwzględnie odpowiada operator instalacji. Jakiekolwiek podane dane nie zwalniają operatora z konieczności krytycznego podejścia do propozycji zawartych w źródłach literaturowych, w tym zwłaszcza wartości wskaźników emisyjnych.

Prosimy cytować jako: Nafta-Gaz 2017, nr 4, s. 287-292, DOI: 10.18668/NG.2017.04.09

Artykuł nadesłano do Redakcji 30.11.2016 r. Zatwierdzono do druku 20.02.2017 r.

Artykuł powstał na podstawie pracy statutowej pt.: Opracowanie metodologii obliczania wielkości emisji zanieczyszczeń do powietrza z instalacji energetycznego i nieenergetycznego spalania paliw towarzyszacych eksploatacji złóz ropy naftowej i gazu ziemnego - praca INiG - PIB na zlecenie MNiSW; nr zlecenia: 0017/SN/16, nr archiwalny: DK-4100-0017/16.

\section{Literatura}

[1] American Petroleum Institute (API), Compendium of Greenhouse Gas Emissions Methodologies for the Oil and Natural Gas Industry, 2009.

[2] EMEP/EEA Air Pollutant Emission Inventory Guidebook - 2013, Oil - Exploration, production, transport, Technical guidance to prepare national emission inventories, 2013.

[3] Instytut Nafty i Gazu - Państwowy Instytut Badawczy; Badanie jakości gazu ziemnego w sieci dystrybucyjnej realizowanej dla PGNiG S.A. w latach 2013-2014

[4] Krajowy Ośrodek Bilansowania i Zarządzania Emisjami (KOBiZE); Wskaźniki emisji zanieczyszczeń ze spalania paliw - kotty o nominalnej mocy cieplnej do $5 \mathrm{MW}, 2015$.

[5] Krajowy Ośrodek Bilansowania i Zarządzania Emisjami (KOBiIZE); Wybrane obowiąki sprawozdawcze wynikające z przepisów prawa międzynarodowego, unijnego oraz krajowego $w$ zakresie ochrony powietrza, 2011.

[6] Krajowy Ośrodek Bilansowania i Zarządzania Emisjami; http://www. kobize.pl/ (dostęp: 18.11.2016).

[7] Ministerstwo Ochrony Środowiska, Zasobów Naturalnych i Leśnictwa; Materiały informacyjno-instruktażowe, Wskaźniki emisji substancji zanieczyszczajacych wprowadzanych do powietrza z procesów energetycznego spalania paliw; seria 1/96, Warszawa 1996.

[8] Niemczewska J., Zaleska-Bartosz J.: Wymagania dotyczace ewidencji i sprawozdawczości $w$ zakresie emisji do powietrza zanieczyszczeń towarzyszacych eksploatacji złóż ropy naftowej i gazu ziemnego. Nafta-Gaz 2016, nr 10, s. 851-856, 10.18668/NG.2016.10.10.

[9] Portal internetowy „Wszystko o emisjach”; http://wszystkooemisjach.pl/ (dostęp: 18.11.2016)
[9] Steczko K., Dobrzańska M.: Krajowe górnictwo naftowe i gazownictwo w obliczu współczesnych wyzwań ekologicznych i polityki ekologicznej Wspólnoty Europejskiej. Nafta-Gaz 2010, nr 12, s. 1115-1122.

[10] U.S. Environmental Protection Agency (US EPA); Emission Factor Documentation for AP-42 Section 1.4 Natural Gas Combustion, 1996.

\section{Akty prawne i normatywne}

[11] Rozporządzenie Ministra Środowiska z dnia 30 października 2014 r. w sprawie wymagań w zakresie prowadzenia pomiarów wielkości emisji oraz pomiarów ilości pobieranej wody (Dz.U. z 2014 r., poz. 1542).

[12] Ustawa z dnia 17 lipca 2009 r. o systemie zarzadzania emisjami gazów cieplarnianych i innych substancji (Dz.U. z 2015 r., poz. 2273).

[13] Ustawa z dnia 27 kwietnia 2001 r. Prawo ochrony środowiska (Dz.U z 2016 r., poz. 672).

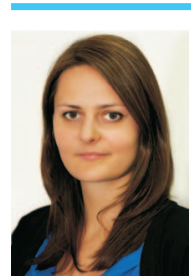

Mgr Joanna NIEMCZEWSKA

Asystent w Zakładzie Ocen Środowiskowych.

Instytut Nafty i Gazu - Państwowy Instytut Badawczy

ul. Lubicz 25 A

31-503 Kraków

E-mail:joanna.niemczewska@inig.pl 